\title{
Disability Of Gait In Stroke Survivors: Physiotherapy Clinical Use Of Visual Gait Analysis In Lusaka, Zambia
}

\author{
${ }^{1 *}$ Brian Chanda Chiluba and ${ }^{2}$ Mulenga Gideon Mwansa \\ ${ }^{1}$ The University of Zambia, School of Health Sciences, PO Box 50110, Lusaka, Zambia \\ ${ }^{2}$ The University of Zambia, School of Health Sciences, Department of Physiotherapy PO Box 50110, Lusaka, Zambia
}

\begin{abstract}
Stroke is one of the leading causes of severe handicap, disabling and impairing the ability to walk in $80 \%$ of all stroke survivors. Physiotherapists, all over the globe, use Observational gait analysis as a preferred method of gait assessment in their clinical practice to assess, monitor change, evaluate treatment and identify areas needing intervention in the rehabilitation of patients with gait disability. The objective of the study was to determine factors affecting the use of observational gait analysis in assessment of stroke survivors among physiotherapy practitioners at the University Teaching Hospital. The study was a cross sectional descriptive study aimed at determining the knowledge and factors affecting use of observational gait analysis and the adaption thereof as a Standard Observational Gait Assessment Tool at the University Teaching Hospital. The essential factors to the use of assessment tools were lack of guidelines and lack of knowledge on use of OGA. Also a lack of organizational support, lack of formal knowledge and no availability of assessment tools. To overcome these barriers, it is necessary to provide training of standardized assessment, and to recommend appropriate guidelines.
\end{abstract}

Keywords: Disability; Assessment; Observational; Gait analysis; Stroke; Physiotherapy practitioner

\section{Introduction}

Stroke is one of the leading causes of severe handicap. Impairment of walking ability is one of the most important determinants of disability in adults with stroke (Chau et al, 2009). Gait disability among stroke patients is a very common symptom that is observed in $80 \%$ of all patients (Chiou \& Burnett, 1985). Gait is a major determinant of independent living; therefore, it is not surprising that improvement of walking function is the most commonly stated priority of stroke survivors (Maher \& Williams, 2005). Approximately $80 \%$ of stroke survivors achieve this goal, though the quality of walking performance often limits endurance and quality of life. Considerable time and resources by both patients and clinicians are invested into rehabilitation focused on the restoration of walking ability following stroke

\footnotetext{
* Corresponding author: Brian Chanda Chiluba brian.chiluba@unza.zm

Published online at http://IJDS.ub.ac.id/

Copyright (C) 2019PSLD UB Publishing. All Rights Reserved
}

and reducing functional dependence (Bohannon et al, 1991).

Physiotherapists, world over, use Observational gait analysis as a preferred method of gait assessment in their clinical practice. The assessment may be used both as a measure (e.g. to monitor change and evaluate treatment) and as a diagnostic tool, to identify areas needing intervention. OGA involves a subjective assessment of an individual's gait, but experienced individuals are often able to visually identify many of the same gait abnormalities that can be discerned with quantitative (computerized) gait analysis (Wade $\%$ Langthon-Hewer, 2009). This approach is based on visual assessment of joint displacement and spatiotemporal components, [6] and it may be supported by video recording, which allows slow motion and freeze-frame analysis. Physiotherapy practitioners have been able to use visual only with the help of gait assessment tools to diagnose gait problems. 
The advantage of OGA in the clinical setting is its simplicity and low cost compared with instrumented gait analysis systems (Wallmann, 2010). Physiotherapists in one study, identified observation of walking as a valuable assessment method, and, for some, it was the only method and also noted that those in acute care were the least likely to use standardized assessment tools due to the short length of hospital stay and high level of patient disability (Pattison et al, 2015). However, in visual gait assessment, standardized procedures are not commonly used (Toro et al, 2013). Professionals tend to identify their own "core set" of gait descriptors, which often are not exhaustive and have a wide variability, whereas the use of assessment tools improves the analyses and helps avoid omissions of important gait issues (Watelain et al, 2005).

Furthermore, accurate assessment of gait kinematics may help predict the degree of improvement and future functional conditions (Kaczmarczyk et al, 2012), plan appropriately targeted treatments, and monitor efficacy of interventions (Kaczmarczyk et al, 2009). Hence, various tools for OGA are used in physiotherapy education programs to facilitate learning of gait kinematics and its deviations to help assist in accurate assessment of gait kinematics (Rosamond et al, 2007). In Zambia, kinesiology and biomechanics are curriculum courses offered in third year during the bachelor's degree of physiotherapy at the University of Zambia. This course equips learners with knowledge of normal gait kinematics and kinetics, and its deviations. A number of gait assessment tools or scales have been developed and adapted worldwide for the purpose of assessment and identification of gait deviations. For example, Rivermead Visual Gait Assessment (RVGA) (Hendricks et al, 2002), Gait Assessment and Intervention Tool, Tinetti gait scale, Winscosin Gait scale (WGS) (Ferrarello et al, 2013), Ranchos observational gait analysis etc. just to mention a few.

Observational (Visual) gait assessment is particularly appealing for clinicians because of its ease, rapidity, simplicity, and low cost of use in comparison with instrumental gait analysis systems. As such, it helps to give an overall impression of an individual's gait pattern and helps to determine any gross abnormalities that may exist (Swinkles et al, 2011). However, OGA has limitations over computerized gait analysis because it cannot determine the biomechanical causes of an abnormal gait. Nevertheless, gait analysis is the best way to objectively assess the technical outcome of a procedure designed to improve gait (Brian et al, 2017). This study is designed to identify factors that could be affecting the use and adaptation of any of the available OGA assessment tools in the stroke patient assessment at UTH.

Stroke severely affects walking ability, and assessment of gait kinematics is important in defining diagnosis, planning treatment, and evaluating interventions in stroke rehabilitation. Although OGA is the most common approach to evaluate gait kinematics, tools useful for this purpose have received little attention in the scientific literature and have not been thoroughly reviewed (Chiluba er al, 2017).

According to Toro, et al, standardized gait assessment tools are widely available in the literature, but they have not been adopted, suggesting that other factors influence adoption. Clearly, the researcher has never come across a standard gait assessment tool in his years of study. Furthermore, in one study it was identified that observation of walking by physiotherapist was a valuable assessment method, and, for some, it was the only method they preferred using (Kaczmarczyk et al, 2009). This prompted the researcher to determine factors that might be limiting the use of such assessment tools in the assessment of gait in stroke patients.

Therefore, this study will establish the knowledge on the use of OGA in stroke patient assessment; determine factors that lead to little use and a lack of an assessment tools in assessment of gait in stroke patients. When information from the study is obtained, it will help save as a first step in the adaptation of a gait assessment tool and to help physiotherapy practitioners gain insight in the utilization of an internationally recognized assessment tools. It will help physiotherapy practitioners in Zambia to correctly diagnose, plan appropriately targeted treatments, and monitor efficacy of interventions of patients with gait impairments. Furthermore, this study will also form a basis for further research.

\section{Research Methodology}

\subsection{Design and setting}

This was a cross sectional descriptive 177

study, utilizing a quantitative research method 
which is aimed at determining the knowledge and factors affecting use of OGA, as well as the adaption of OGA assessment tool at UTH, Physiotherapy department. This study was conducted at the University Teaching Hospital, physiotherapy department which is located in Lusaka, the capital city of Zambia. The University Teaching Hospital was selected because it is the biggest hospital in Zambia and is the nation's tertiary referral hospital with the largest physiotherapy department. This study setting was chosen because it is easily accessible and familiar to the researcher.

\subsection{Study Procedures}

The study population comprised of all 36 Physiotherapy practitioners at UTH. Assessment of subjects' knowledge and determination of factors affecting use of OGA by Physiotherapy practitioners was carried out using a semi structured self-administered questionnaire based on previous studies which was adapted and used to collect data (Kaczmarczyk et al, 2009). The questionnaire was divided into four (4) parts A, B, C and D.

\subsection{Analysis}

Analysis was done using SPSS (Statistical Package for Social Sciences) version 20.0. Knowledge of use of OGA was compared among physiotherapists and technologists and determine whether there is a demographic variable one's experience and its significance in gait assessment of stroke patients.

\section{Results and Discussion}

\subsection{Knowledge Of OGA And Any Gait Assessment Tool}

The results show that $71.4 \% \quad(n=15)$ of physiotherapy practitioners have strongly heard of OGA and a gait assessment tool and $14.3 \%(n=3)$ had never heard of OGA or any assessment tool.

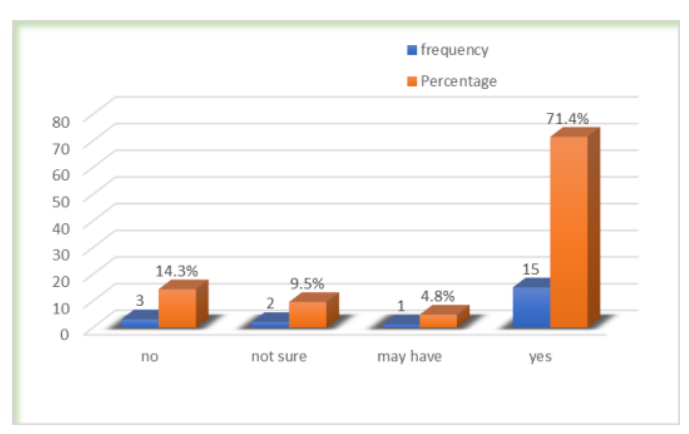

Fig 1. Knowledge Of OGA And Any Gait Assessment Tool Among The Physiotherapy Practitioners At UTH

\subsection{Training Of OGA Among Physiotherapy Practitioners}

The results indicate that $61.9 \%(n=13)$ never underwent training of OGA and only $38.1 \%$ had basic training of OGA. Most of them underwent this training at Diploma level.

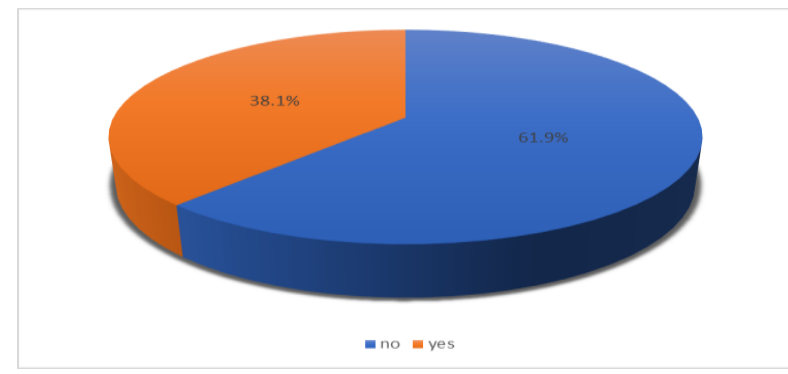

Fig 2. Shows How Many Underwent Training Of The Use Of OGA

\subsection{Knowledge On The Observational Gait Assessment Tools}

Results indicate that 7 physiotherapy practitioners know the Hemiplegic gait analysis form followed by 3 who know the Gait Assessment and Interventional Tool (G.A.I.T).

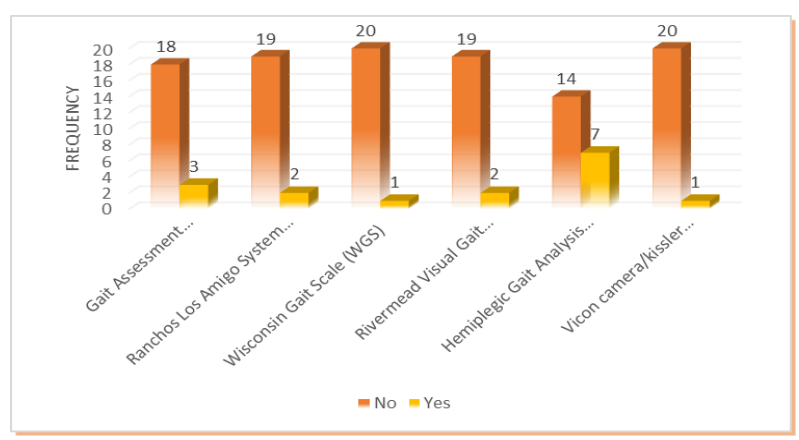

Fig 3. Frequency Of Gait Assessment Tool

\subsection{Perceived Knowledge On The Use Of OGA Assessment Tool Among Physiotherapy Practitioners}

The results show that OGA is moderately easy to use if it were made available $(\mathrm{n}=6,28.6 \%)$ and $9.5 \%(n=2)$ said it was not easy to use. Whereas, $28.6 \%(\mathrm{n}=6)$ had no idea at all. 


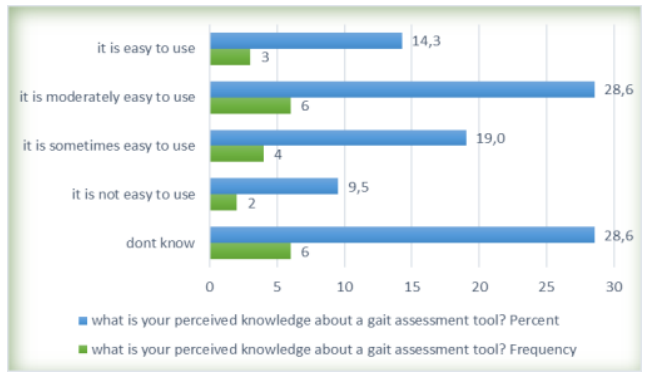

Fig 4. Perceived knowledge on the use of OGA

\subsection{Factors Affecting Use Of OGA And Adaption Of A Gait Assessment}

Tool

Tables 2 and 3 Shows the factors affecting use of OGA and adaption of a gait assessment tool, respectively. The 4 main factors affecting use of OGA were 'lack of guidelines on the use of OGA $(80.9 \%)$, lack of knowledge on use of OGA $(76.2 \%)$, lack of time caused by busy clinical settings $(47.6 \%)$ and low priority $(47.6 \%)$. Whereas, $66.7 \%$ of physiotherapy practitioners disagreed to 'lack of space' as a factor affecting its use.

The 5 main factors affecting adaptation of a gait assessment tool were lack of organizational support (71.4\%), lack of formal knowledge (66.7\%), no availability of assessment tools (61.9\%), lack of time of the initial assessment (33.4\%) and no appropriate tool for the population (33.3\%). Whereas, $61.9 \%$ physiotherapy practitioners disagreed to 'lack of time of the initial assessment', followed by 'existence of numerous assessment tools $(57.2 \%)$ and expensive equipment's $(42.8 \%)$, as factors affecting the adaptation of gait assessment tool in the department.

Table 2. Factors Influencing The Use Of OGA Among Physiotherapy Practitioners (N=21)

\begin{tabular}{lccccc}
\hline & Not sure & $\begin{array}{l}\text { Strongly } \\
\text { disagree }\end{array}$ & Disagree & Agree & Strongly agree \\
\cline { 2 - 5 } & $\mathrm{n}(\%)$ & $\mathrm{n}(\%)$ & $\mathrm{n}(\%)$ & $\mathrm{n}(\%)$ & $\mathrm{n}(\%)$ \\
\hline $\begin{array}{l}\text { Lack of time caused by } \\
\text { busy clinical settings }\end{array}$ & $4(19.0)$ & $1(4.8)$ & $6(28.6)$ & $7(33.3)$ & $3(14.3)$ \\
\hline $\begin{array}{l}\text { Lack of knowledge on } \\
\text { the use of OGA }\end{array}$ & $2(9.5)$ & $2(9.5)$ & $1(4.8)$ & $9(42.9)$ & $7(33.3)$ \\
\hline $\begin{array}{l}\text { Low priority } \\
\text { Lack of guidelines on }\end{array}$ & $2(9.5)$ & $0(0.0)$ & $2(9.5)$ & $10(47.6)$ & $7(33.3)$ \\
the use of OGA & $4(19.0)$ & $0(0.0)$ & $7(33.3)$ & & \\
\hline $\begin{array}{l}\text { Excessive or low } \\
\text { assessment cost }\end{array}$ & $9(42.9)$ & $2(9.5)$ & $9(42.9)$ & $1(4.8)$ & $0(0.0)$ \\
\hline Ease of use & & & & & \\
\hline Lack of space & $8(38.1)$ & $1(4.8)$ & $7(33.3)$ & $4(19.0)$ & $1(4.8)$ \\
\hline
\end{tabular}


Table 3. Factors Influencing Adaptation A Gait Assessment Tool Among Physiotherapy Practitioners $(\mathrm{N}=21)$

\begin{tabular}{lccccc}
\hline & Not sure & $\begin{array}{c}\text { Strongly } \\
\text { disagree }\end{array}$ & Disagree & Agree & $\begin{array}{c}\text { Strongly } \\
\text { agree }\end{array}$ \\
& $\mathrm{n}(\%)$ & $\mathrm{n}(\%)$ & $\mathrm{n}(\%)$ & $\mathrm{n}(\%)$ & $\mathrm{n}(\%)$ \\
\hline Expensive equipment's & $6(28.6)$ & $4(19.0)$ & $5(23.8)$ & $4(19.0)$ & $2(9.5)$ \\
\hline Lack of formal knowledge & $2(9.5)$ & $2(9.5)$ & $3(14.3)$ & $9(42.9)$ & $5(23.8)$ \\
\hline $\begin{array}{l}\text { Lack of time of the initial } \\
\text { assessment }\end{array}$ & $1(4.8)$ & $2(9.5)$ & $11(52.4)$ & $6(28.6)$ & $1(4.8)$ \\
\hline No availability of tools & $5(23.8)$ & $1(4.8)$ & $2(9.5)$ & $5(23.8)$ & $8(38.1)$ \\
\hline $\begin{array}{l}\text { No tool appropriate for the } \\
\text { population }\end{array}$ & $6(28.6)$ & $2(9.5)$ & $6(28.6)$ & $3(14.3)$ & $4(19.0)$ \\
\hline $\begin{array}{l}\text { Lack of organizational } \\
\text { support }\end{array}$ & $2(9.5)$ & $2(9.5)$ & $2(9.5)$ & $12(57.1)$ & $3(14.3)$ \\
\hline $\begin{array}{l}\text { Existence of numerous } \\
\text { assessment tools }\end{array}$ & $3(14.3)$ & $6(28.6)$ & $6(28.6)$ & $5(23.8)$ & $1(4.8)$ \\
\hline
\end{tabular}

\section{Discussion}

The study set out to determine factors affecting the use of observational gait analysis (OGA) in assessment of stroke survivors among physiotherapy practitioners at the University Teaching Hospital. In this study we found that the majority of the practitioners expressed their perceived knowledge of the use of OGA assessment tool as one that is moderately easy to use. This information is consistent with a study conducted by Wallmann, who expressed its simplicity and advantage of using OGA assessment tool (Watelain et al, 2005). In general, level of qualification was clearly linked to a higher perceived knowledge on the use of OGA and a gait assessment tool. However, the opposite was true. There was no linkage between the level of qualification and the knowledge of the use of OGA and any assessment tool. This could be an experiencebased score, because those with degrees and diplomas were older and more experienced and well exposed.

The study also found that the majority of the physiotherapy practitioners had no perceived knowledge of the use of OGA assessment tool. This has a negative impact on the use of an assessment tool as shown a study by McGinnis et al. who observed that 'therapists' knowledge was a critical determinant in the application of a gait assessment tool" (Chiluba et al, 2017). Toro et al. also added that, "clinician performance in using an observation-based gait assessment tool depended upon experience, training, and underlying knowledge of gait, which clearly differs in different clinical settings." This is in agreement with the finding from our study.

Our study found that the most common factors affecting use of OGA at UTH among physiotherapy practitioners were lack of guidelines and lack of knowledge on use of OGA. This was consistence with a study done by Jang, et al., which reported that essential barriers to the use of gait assessment tools were lack of knowledge, low priority, lack of time, too high or low assessment cost and organizational support. In another study conducted by Pattison, he suggested that lack of guidelines, ease of use, time, space, and cost are contributing factors that influence the use of gait assessment tools in patients with stroke. In a different study by Sibley and Salbach, they reported that lack of knowledge was the most critical barrier to the use of assessment tools (Victoria et al, 2018). While other studies found that lack of knowledge was the second most predominant factor affecting use of a gait assessment tool (Kaczmarczyk et al, 2009) The results of similar studies confirm that lack of guidelines and knowledge are among the most common barriers affecting the use of an observational gait analysis assessment tool.

The study also found that the majority of the practitioners disagreed to 'lack of space' as a factor affecting its use. This was however 
inconsistence with what Pattison found (Watelain et al, 2005). This could be attributed to the fact that Pattison was considering the use of gait assessment laboratory equipped with computerized tools, however, this study stringently considered observational gait assessment tool like a scale or form.

The study also found that lack of time due to busy clinic schedule was not a contributing factor. This finding was contradicting with a study done by Jang, et al. who eluded to time as being the most significant barrier in the application of an assessment tool in a clinical setting (Toro et al, 2013). This inconsistence could be as result of changes and diversification of labour in the department, hence according most therapist the time to assess patients comprehensibly.

Our study also found that low priority was a contributing factor to the use of OGA among Physiotherapists. This finding is in line with a study among Canadian physiotherapists who also attributed to low priority as a contributing factor. This is possible because most therapists have busy clinical schedules and therefore get overwhelmed to prioritize and carry out a comprehensive gait assessment.

In this study, we found a significant relationship between years of professional experience and knowledge on the use of OGA and gait assessment tool. Our finding was consistent with a review by Duncan and Murray, who revealed that therapists' knowledge was related to their use of assessment tools (Kaczmarczyk et al, 2009). It was not surprising that physiotherapist with more numbers of years of professional experience had more knowledge on the use of OGA as oppose to those with fewer professional years, because this relates to their more focused practice, experience and extended studies. The need for training was clearly identified in the responses for who underwent gait assessment training. The deficit in gait assessment training could be best addressed by increasing training in gait assessment in the curriculum at diploma and undergraduate levels. This approach would equip physiotherapists with the necessary knowledge and skills in gait assessments. Physiotherapists needs to be specifically trained to use a gait assessment tool, though this training is not sufficient at bachelor's degree and diploma level. This is seen by the way they respondent to whether they underwent training or not.

Standardized gait assessment tools are widely available in the literature (Chiluba et al, 2017), but they have not been adopted, suggesting that other factors influence adoption. In this study we found that the most common factors affecting the adaptation of an assessment tool were lack of organizational support, lack of formal knowledge and no availability of assessment tools. This is in agreement with studies done by Duncan and Murray, and Pattison, et al (Chuni et al, 2018), who also found that lack of organizational support and lack of formal knowledge among the participants were the contributing factors to adoption of a gait assessment tool.

Expensive equipment was not a contributing factor to adaption of an assessment tool. The possible explanation for this is that the therapists saw it feasible for the organization (UTH) to purchase instruments like a video camera which can enable the therapist to slow motion and freeze-frame analysis. Use of a video camera in conjunction with OGA has been highly recommended by therapists. Lack of equipment maybe be related to lack of organizational support. Therefore, there is need to engage the hospital administration and lobby for funds.

In this study we found that most physiotherapy practitioners disagreed to lack time of time of the initial assessment, existence of numerous assessment tools and expensive equipment's as factors affecting the adaptation of gait assessment tool in the department. This was inconsistence with what Jang et al found when he stated that, "the fact that there are numerous assessment tools used for clinical or academic purposes, was a barrier" [9]. In my opinion the difference could be attributed to the fact that UTH has never used any gait assessment tool and so most practitioners have not had any experience of using multiple assessment tools. Moreover, for an accurate gait assessment, it is important to select an assessment tool appropriate for a patient's physical ability and population, however, this is challenging. While in some countries, multiple assessment tools for gait assessment is recommended. 


\section{Conclusion}

Knowledge is an essential element that enables professionals to conduct evidencebased practice and to make decisions from a professional point of view. In this study, majority of physiotherapy practitioners had adequate knowledge on the use of OGA and an assessment tool and stated their enthusiasm to use it if it were made available. The participant's enthusiasm to use the assessment tool is reflected by the fact that more than half of the participants showed keen interest in utilizing the gait assessment tool once given a chance. This response justifies the development of a new, clinically focused gait assessment tool in the department for patients with gait disorders. This tool must address pragmatic issues and not be at the cost of scientific quality. This can be achieved through a more integrated approach to the tool's development and implementation. Unfortunately, these barriers to gait assessment make it difficult for physiotherapists to use or adopt gait assessment tools. To overcome these barriers, it is necessary to provide training of standardized assessment, and to recommend appropriate guidelines. Thus, it is possible for physiotherapists to perform gait assessment efficiently and accurately.

\section{Acknowledgement}

We acknowledge the anonymous independent editor who spent time going through this work before it was submitted for a publication to a journal.

\section{References}

Chau JP, Thompson DR, Twinn S, et al. (2009). Determinants of participation restriction among community dwelling stroke survivors: a path analysis. BMC Neurol.; 9:49.

Chiou II, Burnett CN (1985). Values of activities of daily living: a survey of stroke patients and their home therapists. Phys Ther;65:901-906.Google ScholarPubMed

Maher C, Williams M (2005). Factors influencing the use of outcome measure in physiotherapy management of lung transplant patients in Australia and New Zealand. Physiother Theory Pract;21:201-217. [PubMed: 16396432]
Bohannon, R.W., Horton, M.G. \& Wikholm, J.B. (1991). Importance of four variables of walking to patients with stroke. International Journal of Rehabilitation research, 14(3), 246250.

Wade, D.T. \& Langton-Hewer, R. (2009). Functional abilities after stroke: Measurement natural history and prognosis. Journal of Neurology, Neurosurgery \& Psychiatry. 50, 177-82.

Lord, S.E., Halligan, P.W. \& Wade, D.T. (1998). Visual gait analysis: the development of a clinical assessment and scale. Clinical Rehabilitation, 12, 107-119.

Wallmann, H.W. (2010). Introduction to Observational Gait Analysis. Home Health Care Management and Practice, 22, 66-68

Pattison KM, Brooks D, Cameron JI, Salbach NM (2015). Factors influencing physical therapists' use of standardized measures of walking capacity post-stroke across the care continuum. Phys Ther 95: 1507-1517.

Toro B, Nester C and Farren P, (2013). A review of observational gait assessment in clinical practice. Physiother Theory Pract ;19:137 -149.Google Scholar CrossRef

Watelain E, Froger J, Rousseaux M, et al. (2005). Variability of video-based clinical gait analysis in hemiplegia as performed by practitioners in diverse specialties. J Rehabil Med; 37:317-324.

Kaczmarczyk K, Wit A, Krawczyk M, et al. (2012). Associations between gait patterns, brain lesion factors and functional recovery in stroke patients. Gait Posture;35:214217.Google Scholar CrossRef PubMed

Kaczmarczyk K, Wit A, Krawczyk M, Zaborski J (2009). Gait classification in post-stroke patients using artificial neural networks. Gait Posture.;30:207-210. Google Scholar CrossRef PubMed

Rosamond W, Flegal K, Furio K, et al (2007). Heart Disease and Stroke Statistics-2007 update: A Report From the American Heart Association Statistics Committee and Stroke Statistics Subcommittee. Circulation; 115(5):e69-e171.

Hendricks HT, van Limbeek J, Geurts AC, Zwarts MJ (2002). Motor recovery after stroke: 
a systematic review of the literature. Arch Phys Med Rehabil; 83(11):1629-37.

Ferrarello Francesco, Valeria Anna Maria Bianchi, Marco Baccini, Gaia Rubbieri, Enrico Mossello, Maria Chiara Cavallini, Niccolò Marchionni, Mauro Di Bari (2013). Tools for Observational Gait Analysis in Patients with Stroke: A Systematic Review. Physical Therapy, Volume 93, Issue 12, 1 December 2013, Pages 1673-1685, https://doi.org/10.2522/ptj.20120344

Swinkles RAHM, van Peppen RPS, Wittink H, et al (2011). Current use and barriers and facilitators for implementation of standardized measures in physical therapy in the Netherlands. BMC Musculoskelet Disord;12. [PMCID: PMC3126762] [PubMed: 21600045]

Brian Chanda Chiluba and Wana Gift Njapawu. Barriers of Persons with Physical Disability over Accessibility and Mobility to Public Buildings in Zambia. Indonesian Journal of Disability Studies (IJDS).2019: Vol. 6(1): PP $53-63$.
Brian Chiluba, Esther Munalula-Nkandu, Chola Nakazwe Daka, Mumbi Chola, Gershom Chongwe. Cardiovascular Disease Risk from Protease Inhibitors-ART for HIV: Retrospective Cohort of University Teaching Hospital, Zambia. Cardiology and Cardiovascular Research. Vol. 1, No. 4, 2017, pp. 98-103. doi: 10.11648/j.ccr.20170104.11

Brian Chiluba, Esther Munalula-Nkandu, Chola Nakazwe Daka, Mumbi Chola, Gershom Chongwe. Cardiovascular Disease Risk from Protease Inhibitors-ART for HIV: Retrospective Cohort of University Teaching Hospital, Zambia. Cardiology and Cardiovascular Research. Vol. 1, No. 4, 2017, pp. 98-103. doi: 10.11648/j.ccr.20170104.11

Victoria Chuni, Brian Chanda Chiluba, Moses Mwango, Esther Munalula-Nkandu, Hastings Shula. An Exploration of the Knowledge of Informal Caregivers on Ageing Related Health Conditions at Matero and Chawama Old People's Homes, Zambia. International Journal of Neurologic Physical Therapy. Vol. 4, No. 1, 2018, pp. 1-6. doi: 10.11648/j.ijnpt.20180401.11 